Sourire (singer) suicide among women only. No effect was found after Nino Ferrer (singer) and Gilles Deleuze (philosopher) suicides. Some of these suicides were strongly covered by the media; a qualitative analysis showed that, in most of cases, media did not follow the existing guidelines about suicide report.

Discussion Suicide contagion description and comprehension can help us to lead preventive actions, and to raise medias awareness of the existing guidelines.

\title{
0858 SUICIDE CONTAGION IN FRANCE: AN EPIDEMIOLOGIC
} STUDY

R Queinec*, C Benjamin, C Beitz, E Lagarde, G Encrenaz Correspondence: Psychiatric Hospital, CHS Cadillac, 89 rue Cazeaux Cazalet 33410, France

\subsection{6/ip.2010.029215.858}

Background Werther effect is a type of suicide contagion by which the media coverage following the suicide of a famous person entails a significant increase in the number of suicides. Our objective was to determine whether such an effect had been already experienced in France, where the phenomenon has never been documented. Our hypothesis was that there was a significant increase in the national number of suicides following (+1 month) a celebrity suicide.

Methods We obtained French daily data on suicides from 1979 to 2006 from the CepiDC (INSERM). We selected the six most famous celebrities whose suicide occurred within this period. They were those whose name appeared at least 100000 times in a popular web search engine. Data were analysed using the Seasonal ARIMA model.

Results Pierre Beregovoy (politician) and Kurt Cobain (musician) suicides were followed by a significant increase in the number of suicides in the French general population $(+17.7 \%$ and $+9.2 \%$ respectively). Dalida (singer) suicide had a significant effect among people aged from 45 to 59 only and Soeur 